\title{
Inter- and intra-rater reliability for measurement of range of motion in joints included in three hypermobility assessment methods
}

Angela Schlager ${ }^{1 *} \mathbb{D}$, Kerstin Ahlqvist ${ }^{1}$, Eva Rasmussen-Barr ${ }^{2}$, Elisabeth Krefting Bjelland ${ }^{1,3}$, Ronnie Pingel ${ }^{1}$, Christina Olsson ${ }^{2,4}$, Lena Nilsson-Wikmar ${ }^{2,4}$ and Per Kristiansson ${ }^{1}$

\begin{abstract}
Background: Comparisons across studies of generalized joint hypermobility are often difficult since there are several classification methods and methodological differences in the performance exist. The Beighton score is most commonly used and has been tested for inter- and intra-rater reliability. The Contompasis score and the Hospital del Mar criteria have not yet been evaluated for reliability. The aim of this study was to investigate the inter- and intra-rater reliability for measurements of range of motion in joints included in these three hypermobility assessment methods using a structured protocol.
\end{abstract}

Methods: The study was planned in accordance with guidelines for reporting reliability studies. Healthy adults were consecutively recruited (49 for inter- and 29 for intra-rater assessments). Intra-class correlations, two-way random effects model, (ICC 2.1) with 95\% confidence intervals, standard error of measurement, percentage of agreement, Cohen's Kappa (K) and prevalence-adjusted bias-adjusted kappa were calculated for single-joint measured in degrees and for total scores.

Results: The inter- and intra-rater reliability in total scores were ICC 2.1: 0.72-0.82 and 0.76-0.86 and for single-joint measurements in degrees $0.44-0.91$ and $0.44-0.90$, respectively. The difference between ratings was within 5 degrees in all but one joint. Standard error of measurement ranged from 1.0 to 6.9 degrees. The inter- and intrarater reliability for prevalence of positive hypermobility findings the Cohen's $\mathrm{k}$ for total scores were $0.54-0.78$ and 0 . 27-0.78 and in single joints $0.21-1.00$ and 0.19-1.00, respectively. The prevalence- and bias adjusted Cohen's K, increased all but two values.

Conclusions: Following a structured protocol, the inter- and intra-rater reliability was good-to-excellent for total scores and in all but two single joints, measured in degrees. The inter- and intra-rater reliability for prevalence of positive hypermobility findings was fair-to-almost perfect for total scores and slight-to-almost-perfect in single joints. By using a structured protocol, we attempted to standardize the assessment of range of motion in clinical and in research settings. This standardization could be helpful in the first part of the process of standardizing the tests thus avoiding that assessment of GJH is based on chance.

Keywords: Generalized joint hypermobility, Inter- and intra- reliability, Beighton score, Contompasis score, Hospital del mar criteria, Joint mobility assessment, Standardized protocol, Goniometer, Range of motion

\footnotetext{
* Correspondence: angela.schlager@pubcare.uu.se

A Schlager and K Ahlqvist equally contributed to the study as first authors

1 Department of Public Health and Caring Sciences, Uppsala University,

Husargatan 3, Box 564, 75237 Uppsala, Sweden

Full list of author information is available at the end of the article
}

(c) The Author(s). 2018 Open Access This article is distributed under the terms of the Creative Commons Attribution 4.0 International License (http://creativecommons.org/licenses/by/4.0/), which permits unrestricted use, distribution, and reproduction in any medium, provided you give appropriate credit to the original author(s) and the source, provide a link to the Creative Commons license, and indicate if changes were made. The Creative Commons Public Domain Dedication waiver (http://creativecommons.org/publicdomain/zero/1.0/) applies to the data made available in this article, unless otherwise stated. 


\section{Background}

Generalized joint hypermobility (GJH), defined as an increased range of motion ( $\mathrm{ROM}$ ) in several joints [1], is associated with longstanding musculoskeletal problems [2]. Many people with GJH seek primary care for pain and activity limitations [3, 4].

Joint ROM varies greatly in the general population $[5,6]$ and a joint ROM above two standard deviations from the average is suggested to be hypermobile [7]. The prevalence of GJH varies across gender, age, ethnicity and according to assessment methods and their cut-off points [8]. In Sweden, GJH is estimated to be present in approximately $10 \%$ of the general population [9].

Although GJH is an important criterion in the diagnosis of many heritable connective tissue disorders $[3,5]$ no agreed criteria exist $[5,10,11]$. Furthermore, which joints to include in diagnosing GJH has been debated [12]. The Beighton score (BeS) [13], which is a development of the Carter and Wilkinson score [14], is the most common diagnostic test for GJH worldwide [8, 15]. The $\mathrm{BeS}$ demonstrates good inter- and intra-rater reliability [15-17] but with conflicting evidence and methodological flaws [18]. Advantageously, the $\mathrm{BeS}$ is quick and easy to perform. However, the BeS only covers five joints particularly hinge joints and is an "all-or-none-test" with no indication regarding the degree of hypermobility [13]. Commonly used cut-off levels in the BeS vary between $\geq 4$ and $\geq 5$ for diagnosing GJH in adults [18].

Another assessment method is the Contompasis score (CS), a modification of the BeS which includes one additional joint. The CS is measured by grading the ROM and might be considered more time-consuming [19]. Furthermore, the Hospital del Mar criteria (HdM), which is a development of the Rotés-Querol, offer a wider view of joint mobility by assessing nine joints, including ball-and-socket-joints [12]. To our best knowledge, the inter- and intra-rater reliability of the CS and the HdM scores have not yet been evaluated.

Comparisons across studies of GJH assessments are hampered because a structured protocol is often lacking [20-23]. Neither the literature nor the criteria for diagnosis of $\mathrm{GJH}$ [3] and heritable connective tissue disorders [24] describes the test performances in detail [10, 18]. Although ROM measured in degrees using a goniometer has shown better inter-rater reliability, assessment of GJH is often based on visual assessment $[15,17,25]$ with a dichotomous principle of judgement. The reliability is also affected by the joint structure, the level of pre-training and experience among the raters [26].

To identify people with GJH and subsequently tailor suitable interventions, reliable clinical assessment methods are important. Thus, there is a need for international consensus regarding performance, cut-off levels and interpretation of clinical assessments based on reliability studies of high quality $[11,18]$ to reduce the likelihood that the assessment of GJH is based on chance. Before deciding on the validity of these tests the reliability needs to be investigated in a standardized manner [18].

The aim of this study was to investigate the inter- and intra-rater reliability for measurements of ROM in joints included in three hypermobility assessment methods using a structured protocol.

\section{Methods \\ Design}

An inter- and intra-reliability study.

This study was planned and developed in accordance with "Guidelines for Reporting Reliability and Agreement Studies" (GRRAS) and "Quality Appraisal of Reliability Studies” (QAREL) [27, 28].

\section{Structured protocol and instruments}

This study assessed inter- and intra-rater reliability of three hypermobility assessment methods, the BeS, the CS and the HdM for measuring joint ROM using a test-retest design which comprised in total 12 single joints. A protocol was developed to standardize the measurement of joint ROM (Additional file 1), which was further expanded from the original versions of the BeS, the CS and the HdM (Additional file 2). Starting position, positioning of the goniometer, anatomical landmarks, stabilization of adjacent structures and performances, using active or passive movement, were described and illustrated using photographs in the new protocol.

The BeS [13] comprises assessments of five joints, passive dorsiflexion of the fifth finger metacarpophalangeal joint, passive apposition of the thumb, passive hyperextension of the elbow and knee as well as forward flexion of the trunk. The first four joints are assessed bilaterally yielding a total score ranging from 0 to 9 [13]. The BeS scores of $\geq 4$ and $\geq 5$ points were used as cut-off levels for GJH.

The CS [19] comprises the assessment of six joints, which is similar to the BeS but with one additional joint, the foot flexibility test. Five joints are assessed bilaterally with each joint graded from two to six/or eight points with a total score range from 22 to 72 [19]. A cut-off level of $\geq 30$ points for the CS was used to define GJH. The CS scores was modified because ROM in degrees for the elbow, knee and fifth finger were insufficiently graded and some degrees were represented in two score levels in the original description (Additional file 2).

The HdM [12] comprises the assessment of 10 items, passive apposition of the thumb, passive dorsiflexion of the fifth finger, passive hyperextension of the elbow, external shoulder rotation, hip abduction, patella hypermobility, ankle and foot hypermobility, first metatarsophalangeal 
joint, knee hyperflexion and easy bruising. Nine joints are assessed unilaterally on the non-dominant side. The last item deals with bruising; "Do you get bruises easily after minimal trauma?" Each hypermobile item scores one point, yielding a total score ranging from 0 to 10 . The $H d M \geq 4$ and $\geq 5$ were set as cut-off levels for GJH [12]. The HdM measurement was modified by measuring passive opposition of the thumb with a goniometer instead of a ruler where $<15$ degrees on the goniometer corresponds to $<21 \mathrm{~mm}$ on the ruler as used in the original description. Due to the lack of a reference value regarding a positive hypermobility finding for the ankle and the patella, $\geq 45$ degrees was considered as hypermobile for the ankle $[29,30]$. In addition, the measurement of the patella was standardized to make objective assessment possible (Additional file 1).

A goniometer (Medema Brodin, Kista Sweden, $31 \mathrm{~cm}$ or $21 \mathrm{~cm}$ with a $180^{\circ}$ protractor and movable arms) was used. The small goniometer was used for measurements of the fifth finger and the big toe. Each joint was registered to the nearest 1-degree.

\section{Raters}

Two physiotherapists, rater A (KA) and rater B (AS) assessed all of the participants. Both raters had clinical experience in the physical examination of patients with joint hypermobility attending primary care (27 and 24 years of experience respectively). To standardize the performance and to assure similar interpretations of the assessments, the two raters trained un-blinded on three occasions until consensus was reached, for a total of $24 \mathrm{~h}$, before data collection. The training cohort included 21 persons.

\section{Participants}

Information regarding the study was sent by e-mail to all 250 employees in a rehabilitation company within primary care in Stockholm, Sweden. The inclusion criteria were men and women aged between 18 and 65 years. For the inter-reliability study, we recruited the first consecutive 50 individuals who agreed to participate and who met the inclusion criteria. Of these, the first 30 participants were included in the intra-rater reliability study. Individuals with joint inflammatory signs, spasticity, joint-replacement, musculoskeletal injuries during the past 3 months and those who were not fluent in the Swedish language were excluded.

\section{Procedures}

Self-reported sociodemographic data concerning gender, age and country of birth were obtained using a questionnaire. The raters examined the participants in separate examination rooms without the presence of other employees. The participants wore shorts and tank tops. No warming-up sessions were done before assessments. Reference dots were marked by the assessing rater on anatomical landmarks (Additional file 1), and were removed after each assessment session. The rater started each assessment with both oral and visual instructions about how the test would be performed.

The rater instructed the participant to stop the passive movement when they experienced that their joints were at an end-range position. The rater examined if it was possible to move the joint further without causing pain. In measurement of active ROM, the participant was asked: "Is this your maximum ROM?" For inter-raterreliability, the raters assessed the same participant with a minimum of $30 \mathrm{~min}$ and a maximum of $7 \mathrm{~h}$ between assessments. The raters were blinded with respect to each other's results. To avoid recall bias in the intra-raterreliability study, rater B conducted the repeated assessments 7 to 14 days after the first assessment. The second assessment was performed at the same time of the day as the first.

A timetable assured that the time intervals between assessments were achieved and that the order in which raters assessed the participants varied. The order of the joint assessments changed every third assessment day for both inter- and intra-rater reliability examinations by starting from the end of the protocol (Additional file 1).

\section{Statistical analysis}

Statistical analysis was conducted with R.3.3.1 (The R Project for Statistical Computing, Vienna, Austria). Intra-class correlations, two-way random effects model, ICC (2.1) with $95 \%$ confidence intervals (CI), were used to measure the inter- and intra-rater reliability for the quantitative measurements joint ROM (degrees) and total scores of the three hypermobility assessment methods [31]. The two-way models allow the error to be partitioned between systematic and random error [31, 32]. The ICC specific to the total score of the hypermobility assessment methods was used as the majority of these values were based on measured degrees. An ICC-score of $<0.40$ was considered poor, $0.40-0.59=$ fair $/$ moderate, $0.60-0.74=$ good and $\geq 0.75=$ excellent [32]. The standard error of measurement (SEM) quantifies absolute reliability [33] and is referred to as the "typical" error [34]. The SEM was calculated using the residual mean square error from two-way repeated measures ANOVA. The SEM is important since a smaller SEM indicates more reliable results [33]. The value of an accepted SEM is a clinical decision.

For binary variables, the total percentage of agreement $\left(\mathrm{P}_{\mathrm{a}}\right)$ for prevalence of positive findings was calculated. To assess the proportion of agreement beyond that expected by chance Cohen's Kappa ( $\mathrm{k}$ ) was used [35]. A kappa value of $\mathrm{K}=<0.00$ is considered as poor, $0.00-0.20=$ slight, $0.21-$ $0.40=$ fair,$\quad 0.41-0.60=$ moderate,$\quad 0.61-0.80=$ substantial 
and $\geq 0.81$ almost perfect [36]. Since prevalence and bias affect the magnitude of the kappa coefficient, the prevalence-adjusted bias-adjusted kappa (PABAK) was calculated in addition to the obtained value of kappa [35].

With a significance level at 0.05 and a power of $80 \%$, the sample size in this study was based upon an ICC score of at least 0.82 where a score of 0.6 or higher would be acceptable [37].

\section{Results}

Forty-nine adults, 38 women and 11 men, mean (SD) age 39.8 (13.5) years participated in the inter-raterreliability study. Twenty-nine adults, 23 women and 6 men, mean (SD) age 39.9 (12.5) years participated in the intra-raterreliability study. The majority were Europeans, 96\% and 97\% respectively. One participant was excluded because of injury. The time interval from assessments in the inter-raterreliability study varied from $30 \mathrm{~min}$ to $7 \mathrm{~h}$ and between eight to 8 days in the intra-rater reliability study.

The inter- and intrarater-reliability for the total score of all assessment methods, using ICC 2.1, was good-to-excellent $0.72-0.82$ and $0.76-0.86$, respectively (Table 1).

The inter-rater reliability for measurements of joint ROM in degrees was good-to-excellent in all but three of the assessed joints (ICC 2.1: 0.67-0.91). For the hips and right calcaneus the reliability was moderate (ICC 2.1: $0.44-0.59$ ). The differences between raters were within 5 degrees (0.1-4.3) in all but one measurement. The SEM ranged from 1.1 to 6.2 degrees (Table 2).

The intra-rater reliability for measurements of joint ROM in degrees was good-to-excellent in all but three of the assessed joints (ICC 2.1: 0.60-0.90). For left hip and the calcaneus bilaterally the reliability was moderate (ICC 2.1: 0.44-0.51). The differences between test-retest assessments were within 3 degrees $(0.0-2.7)$ in all but one of the measurements. SEM ranged from 1.0 to 5.7 degrees (Table 3).

For inter-rater reliability, the agreement $\left(\mathrm{P}_{\mathrm{a}}\right)$ for the prevalence of positive hypermobility findings ranged from 80 to $98 \%$ for all total scores and Cohen's ( $\mathrm{k}$ ) was moderate-to-substantial $(\kappa=\geq 0.54-0.78)$. The PABAK increased the results $(\kappa=\geq 0.59-0.96)$, (Table 4).
Regarding prevalence of positive hypermobility findings for separate joint assessments, the $\mathrm{P}_{\mathrm{a}}$ ranged from 80 to $100 \%$, except for the calcaneus. Cohen's ( $\mathrm{K}$ ) was substantial-to-almost perfect for 13 of the 21 joint assessments $(K=0.63-1.00)$ while the PABAK was substantial-to-almost perfect in all but three joint assessment $(\kappa=0.63-1.00)$, (Table 4).

For intra-rater reliability, the $\mathrm{P}_{\mathrm{a}}$ for prevalence of positive hypermobility findings ranged from 72 to $97 \%$ for all total assessment scores. Cohen's $(\kappa)$ was fair-to-substantial $(\kappa=0.27-0.78)$ and the PABAK was moderate-to-almost perfect $(\kappa=0.45-0.93)$, (Table 5). For prevalence of positive hypermobility findings regarding single joint assessments, the $\mathrm{P}_{\mathrm{a}}$ ranged from 79 to $100 \%$ excpept for the calcaneus. Cohen's ( $\mathrm{K}$ ) was substantial-to-almost perfect in 13 of the 21 joint assessments $\quad(\kappa=0.61-1.00)$. The PABAK was substantial-to-almost perfect in all but three joint assessment ( $\kappa=0.66-1.00)$, (Table 5).

The inter-and intra-rater reliability for the prevalence of positive hypermobility findings for the hip- abduction are not reported since none of the participants reached the cut off limit of $>85$ degrees (Tables 4 and 5).

\section{Discussion}

To the best of our knowledge, this is the first study to investigate the inter- and intra-rater reliability of the Beighton score, the Contompasis score and the Hospital del Mar criteria. We used a structured protocol including descriptions of testing positions, starting positions, goniometer positions, anatomical landmarks, stabilization of adjacent structures and performance illustrated by photos.

Following this structured protocol with use of a goniometer, all of the three hypermobility assessment methods, the BeS, the CS and the HdM, showed good-to-excellent inter- and intra-rater reliability for the total scores and for the majority of the single-joint measurements in degrees. The SEM for inter-and intra-rater reliability ranged from 1.0 to 6.2 degrees.

Previous reliability studies of the BeS using a protocol have presented similar results to those in this study [12, 15-17, 25, 38, 39]. However, comparisons with these studies are complicated as the testing

Table 1 Inter-and intra-rater reliability of the total score of three hypermobility instruments

\begin{tabular}{|c|c|c|c|c|c|c|c|c|c|c|}
\hline \multirow{2}{*}{$\begin{array}{l}\text { Variable } \\
\text { Hypermobility } \\
\text { instrument }\end{array}$} & \multicolumn{5}{|c|}{ Inter-rater reliability } & \multicolumn{5}{|c|}{ Intra-rater reliability } \\
\hline & $\begin{array}{l}\text { Rater A } \\
\text { mean (SD) }\end{array}$ & $\begin{array}{l}\text { Rater B } \\
\text { mean (SD) }\end{array}$ & $P$-value & $\begin{array}{l}\text { Intra class } \\
\text { correlation }[1,2] \\
(95 \% \mathrm{Cl})\end{array}$ & $\begin{array}{l}\text { Standard error } \\
\text { of measurement }\end{array}$ & $\begin{array}{l}\text { Rating } 1 \\
\text { mean (SD) }\end{array}$ & $\begin{array}{l}\text { Rating } 2 \\
\text { mean (SD) }\end{array}$ & $P$-value & $\begin{array}{l}\text { Intra class } \\
\text { correlation }[1,2] \\
(95 \% \mathrm{Cl})\end{array}$ & $\begin{array}{l}\text { Standard error } \\
\text { of measurement }\end{array}$ \\
\hline Bes & $1.4(1.4)$ & $1.3(1.4)$ & 0.59 & $0.72(0.55-0.83)$ & 0.7 & $1.4(1.6)$ & $1.1(1.4)$ & 0.11 & $0.76(0.54-0.88)$ & 0.7 \\
\hline $\mathrm{HdM}$ & $2.7(1.4)$ & $2.6(1.5)$ & 0.42 & $0.81(0.69-0.89)$ & 0.6 & $2.5(1.2)$ & $2.3(1.2)$ & 0.08 & $0.86(0.73-0.93)$ & 0.4 \\
\hline CS & $28.9(4.3)$ & $28.1(4.1)$ & 0.03 & $0.82(0.69-0.89)$ & 1.8 & $28.4(3.5)$ & $27.4(3.8)$ & 0.02 & 0.79 (0.57-0.90) & 1.6 \\
\hline
\end{tabular}

The hypermobility instruments used in this study were: BeS Beighton score, CS Contompasis score, HdM Hospital del Mar 
Table 2 Inter-rater reliability for measurement of joint mobility measured in degrees in three hypermobility instruments

\begin{tabular}{|c|c|c|c|c|c|c|c|}
\hline Joint & $\begin{array}{l}\text { Hypermobility } \\
\text { instrument }\end{array}$ & $\begin{array}{l}\text { Rater A } \\
\text { mean (SD) }\end{array}$ & $\begin{array}{l}\text { Rater B } \\
\text { mean (SD) }\end{array}$ & $\begin{array}{l}\text { Difference } \\
\text { A-B }\end{array}$ & $P$-value & $\begin{array}{l}\text { Intra class } \\
\text { correlation [1, 2] } \\
(95 \% \text { Cl) }\end{array}$ & $\begin{array}{l}\text { Standard error of } \\
\text { measurement }\end{array}$ \\
\hline 5th Finger, left & BeS, CS, HdM & 76.9 (13.0) & 73.4 (13.8) & 3.5 & $<0.001$ & $0.85(0.69-0.92)$ & 4.7 \\
\hline 5th Finger, right & BeS, CS, HdM & $72.9(14.6)$ & $70.2(14.0)$ & 2.7 & 0.014 & $0.85(0.74-0.92)$ & 5.2 \\
\hline Thumb, left & $\mathrm{BeS}, \mathrm{CS}, \mathrm{HdM}$ & $24.8(11.0)$ & $26.4(10.9)$ & -1.6 & 0.017 & $0.91(0.83-0.95)$ & 3.2 \\
\hline Thumb, right & $\mathrm{BeS}, \mathrm{CS}, \mathrm{HdM}$ & $27.4(11.1)$ & $27.3(9.3)$ & 0.1 & 0.859 & $0.89(0.82-0.94)$ & 3.4 \\
\hline Elbow, left & BeS, CS, HdM & $5.6(3.3)$ & $4.4(3.4)$ & 1.2 & 0.002 & $0.69(0.46-0.82)$ & 1.8 \\
\hline Elbow, right & $\mathrm{BeS}, \mathrm{CS}, \mathrm{HdM}$ & $5.4(3.8)$ & $4.2(3.9)$ & 1.2 & 0.005 & $0.67(0.46-0.81)$ & 2.1 \\
\hline Shoulder, left & $\mathrm{HdM}$ & $62.1(15.5)$ & 60.3 (16.6) & 1.8 & 0.081 & $0.90(0.82-0.94)$ & 5.0 \\
\hline Shoulder, right & $\mathrm{HdM}$ & $63.4(15.0)$ & $61.4(15.9)$ & 2.0 & 0.054 & $0.89(0.81-0.94)$ & 5.1 \\
\hline Calcaneus, left & CS & $3.2(2.2)$ & $2.3(1.8)$ & 0.8 & $<0.001$ & $0.68(0.41-0.83)$ & 1.0 \\
\hline Calcaneus, right & CS & $2.9(1.8)$ & $2.3(1.5)$ & 0.6 & 0.011 & $0.59(0.36-0.75)$ & 1.0 \\
\hline Ankle, left & $\mathrm{HdM}$ & $38.1(5.5)$ & $39.9(6.2)$ & -1.8 & 0.001 & $0.77(0.57-0.88)$ & 2.6 \\
\hline Ankle, right & $\mathrm{HdM}$ & $36.8(6.2)$ & $39.2(6.2)$ & -2.4 & $<0.001$ & $0.82(0.45-0.92)$ & 2.2 \\
\hline Big toe, left & $\mathrm{HdM}$ & 91.5 (10.9) & $97.4(14.3)$ & -5.9 & $<0.001$ & $0.73(0.34-0.88)$ & 5.5 \\
\hline Big toe, right & $\mathrm{HdM}$ & $90.5(12.2)$ & $94.4(15.3)$ & -3.9 & 0.003 & $0.77(0.59-0.87)$ & 6.2 \\
\hline Knee extension, left & $\mathrm{BeS}, \mathrm{CS}$ & $3.4(3.4)$ & $4.0(3.6)$ & -0.7 & 0.023 & $0.81(0.68-0.89)$ & 1.5 \\
\hline Knee extension, right & $\mathrm{BeS}, \mathrm{CS}$ & $3.5(3.1)$ & $4.3(3.7)$ & -0.8 & 0.019 & $0.76(0.60-0.86)$ & 1.6 \\
\hline Hip abduction, left & $\mathrm{HdM}$ & $35.8(5.0)$ & $32.4(6.1)$ & 3.4 & $<0.001$ & $0.44(0.13-0.66)$ & 3.8 \\
\hline Hip abduction, right & $\mathrm{HdM}$ & $34.6(6.6)$ & $30.2(5.8)$ & 4.3 & $<0.001$ & $0.54(0.08-0.77)$ & 3.6 \\
\hline
\end{tabular}

The hypermobility instruments used in this study were: BeS Beighton score, CS Contompasis score, HdM Hospital del Mar

procedures vary. This will affect the measurement of joint ROM [40] and thus influence the results [10]. In addition, many studies reported the use of no $[21,22]$ or an insufficient protocol $[23,25,41,42]$. Comparisons are further hampered due to differences regarding the use or lack of use of a goniometer, reference lines for the goniometer and for anatomical landmarks, insufficient stabilization of adjacent structures, active or passive testing, testing positions, cut-off levels and statistical methods [15-17, 21, 22, 25, 38, 39, 41, 42].

To the best of our knowledge, this was the first interand intra-rater reliability study of the CS and the HdM and the first reliability study using measurement in degrees for joints included in the three hypermobility assessment methods. The inter- and intra-rater reliability was good-to-excellent for the majority of the single-joint assessments. Since prevalence and bias affect the magnitude of Cohen's ( $\mathrm{k}$ ), it is recommended to also calculate the PABAK [35]. Due to adjusting for prevalece and bias, higher PABAK than Cohen's $(\mathrm{k})$ was found across all the results (Tables 4 and 5).

The difference between and within the raters in the present study was less than five degrees in all but one measurement which is in accordance with other studies $[38,43]$. This is within an acceptable measure, as a variation of \pm 5 degrees in goniometric measurements is generally accepted in the clinic $[44,45]$.
The inter-and intra-rater reliability was moderate for some joints, indicating difficulties in the performance of these assessments. Joints without ROM end points, such as the elbow, the fifth finger and the knee might be considered more challenging to measure. This could be the reason why these joints in the BeS showed the lowest kappa values and the lowest $\mathrm{P}_{\mathrm{a}}$ for the prevalence of positive hypermobility findings in this study and as well as in other studies [15, 17, 25, 42]. We stabilized the wrist and the fourth finger when measuring the fifth finger ROM since the test phase showed an increased ROM when the adjacent structures were not stabilized. This may affect the prevalence. Therefore, there is a need for consensus in the performance.

We have not found any documentation regarding the selection of joints for the criteria of the GJH.

In addition to study reliability of the BeS with a structured protocol, this study also aimed to establish the interand intra-rater reliability for the measurement of ROM in joints other than those included in the BeS. Children with joint hypermobility assessed with the BeS were equally hypermobile in their ball-and-socket-joints [43]. Thus, the importance of ball-and-socket-joints in adults with GJH requires further study.

Following this structured protocol with standardized assessments provided an excellent inter- and intra-rater reliability for the measurement of external rotation of the shoulder ICC 2.1: $0.89-0.90$ and $0.86-0.87$, respectively. 
Table 3 Intra-rater reliability for measurement of joint mobility measured in degrees in three hypermobility instruments

\begin{tabular}{|c|c|c|c|c|c|c|c|}
\hline Joint & $\begin{array}{l}\text { Hypermobility } \\
\text { instrument }\end{array}$ & $\begin{array}{l}\text { Rating } 1 \\
\text { mean (SD) }\end{array}$ & $\begin{array}{l}\text { Rating } 2 \\
\text { mean (SD) }\end{array}$ & Difference 1-2 & $P$-value & $\begin{array}{l}\text { Intra class } \\
\text { correlation }[1,2] \\
(95 \% \mathrm{Cl})\end{array}$ & $\begin{array}{l}\text { Standard error of } \\
\text { measurement }\end{array}$ \\
\hline 5th Finger, left & $\mathrm{BeS}, \mathrm{CS}, \mathrm{HdM}$ & 71.5 (12.8) & $71.6(13.2)$ & -0.1 & 0.908 & $0.88(0.77-0.94)$ & 4.5 \\
\hline 5th Finger, right & $\mathrm{BeS}, \mathrm{CS}, \mathrm{HdM}$ & $71.6(13.1)$ & 70.4 (12.9) & 1.2 & 0.312 & $0.88(0.75-0.94)$ & 4.6 \\
\hline Thumb, left & $\mathrm{BeS}, \mathrm{CS}, \mathrm{HdM}$ & $26.3(8.7)$ & $27.3(8.9)$ & -1.0 & 0.207 & $0.89(0.78-0.94)$ & 3.0 \\
\hline Thumb, right & $\mathrm{BeS}, \mathrm{CS}, \mathrm{HdM}$ & $28.6(9.4)$ & $28.6(8.3)$ & 0.0 & 1.000 & $0.90(0.79-0.95)$ & 2.8 \\
\hline Elbow, left & BeS, CS, HdM & $4.8(4.0)$ & $5.2(3.5)$ & -0.4 & 0.551 & $0.60(0.30-0.79)$ & 2.4 \\
\hline Elbow, right & $\mathrm{BeS}, \mathrm{CS}, \mathrm{HdM}$ & $5.4(4.1)$ & $4.2(4.2)$ & 1.2 & 0.040 & $0.71(0.47-0.86)$ & 2.1 \\
\hline Shoulder, left & $\mathrm{HdM}$ & $60.4(15.5)$ & 62.5 (15.6) & -2.1 & 0.175 & $0.86(0.73-0.93)$ & 5.7 \\
\hline Shoulder, right & $\mathrm{HdM}$ & $61.5(13.9)$ & $63.0(15.7)$ & -1.5 & 0.288 & $0.87(0.74-0.94)$ & 5.3 \\
\hline Calcaneus, left & CS & $2.4(1.5)$ & $1.9(1.5)$ & 0.5 & 0.105 & $0.44(0.11-0.69)$ & 1.1 \\
\hline Calcaneus, right & CS & $2.6(1.3)$ & $2.4(1.5)$ & 0.2 & 0.432 & $0.51(0.19-0.74)$ & 1.0 \\
\hline Ankle, left & $\mathrm{HdM}$ & $40.2(5.1)$ & $40.0(6.2)$ & 0.3 & 0.676 & $0.81(0.64-0.91)$ & 2.5 \\
\hline Ankle, right & $\mathrm{HdM}$ & $39.6(6.8)$ & $39.6(6.0)$ & 0.0 & 0.959 & $0.85(0.70-0.93)$ & 2.5 \\
\hline Big toe, left & $\mathrm{HdM}$ & 99.9 (13.4) & 93.5 (14.6) & 6.3 & $<0.001$ & $0.79(0.31-0.92)$ & 5.2 \\
\hline Big toe, right & $\mathrm{HdM}$ & $93.1(14.8)$ & $90.4(16.5)$ & 2.7 & 0.079 & $0.86(0.72-0.93)$ & 5.6 \\
\hline Knee extension, left & $\mathrm{BeS}, \mathrm{CS}$ & $4.4(3.5)$ & $3.9(3.6)$ & 0.5 & 0.285 & $0.77(0.58-0.89)$ & 1.7 \\
\hline Knee extension, right & $\mathrm{BeS}, \mathrm{CS}$ & $4.8(3.4)$ & $4.4(4.1)$ & 0.4 & 0.515 & $0.66(0.40-0.83)$ & 2.2 \\
\hline Hip abduction, left & $\mathrm{HdM}$ & $30.9(5.0)$ & $33.4(5.0)$ & -2.5 & 0.010 & $0.45(0.11-0.70)$ & 3.6 \\
\hline Hip abduction, right & $\mathrm{HdM}$ & $28.8(5.9)$ & $30.5(6.2)$ & -1.7 & 0.062 & $0.67(0.40-0.83)$ & 3.4 \\
\hline
\end{tabular}

The hypermobility instruments used in this study were: BeS Beighton score, CS Contompasis score, HdM Hospital del Mar

In accordance with another study [15], we reported low inter- and intra-rater reliability in measurements of hip-abduction, which may be due to insufficient stabilization of the pelvis. Furthermore, as in the hip-abduction measurement of elbow and calcaneus showed wide confidence intervals. The lack of precision in these measurements, as displayed by the wide CIs, suggests that the reliability should be interpreted with care. For the elbow, this could depend on a large valgus angle that falsely might give an impression of hypermobility [17]. Moreover, it is difficult to evaluate the reliability of the calcaneus tilt since the ROM is within the measurement error of the goniometer. This finding suggests that the calcaneus tilt should be excluded in the assessment of $\mathrm{GJH}$. Other disputable tests included in the HdM are the knee-hyperflexion and the big toe-extension test. Most participants scored positive on these tests even though they were not hypermobile in other joints, suggesting that the risk of a false positive finding in the general population is high. Despite good-to-excellent inter- and intra-rater reliability, these tests are not adequate to identify joint hypermobility, as also confirmed in another study [23]. We therefore propose that these tests should be removed from the HdM. The remarkably high prevalence of positive hypermobility findings for knee-flexion and big toe-extension may have resulted in a higher prevalence of hypermobility in the HdM compared to the BeS in this study.

There was a difference in big toe-extension between right and left side for both inter- and intra-rater reliability, indicating a systematic error. This may be explained by the fact that both raters were right-handed.

None of the participants had hypermobile hip-abduction and few had hypermobile external rotation of the shoulder even though measurements showed hypermobility in other joints. This may indicate that the cut-off value for hypermobility in these joints is too high in the HdM. A too high cut-off value increases the risk of underdiagnosing a possible hypermobility. In accordance with another study [15] cut-off levels for hypermobility above 55 degrees for hip-abduction $[30,46]$ and above 68 degrees for the shoulder external rotation [46] are supported.

We defined cut-off levels for the three hypermobility assessment methods. A cut-off level of the CS $\geq 30$ for GJH was used in this study which corresponds to the BeS cut-off level of $\geq 4$ points [47]. Previous reliability studies concerning the CS also used other cut-off levels $[47,48]$ than in the original description [19]. A cut-off level of $\geq 30$ for the CS had a lower kappa value compared to a cut-off level of $\geq 4$ or $\geq 5$ when using the BeS and the HdM in this study. This may be due to the 
Table 4 Inter-rater reliability for prevalence of positive hypermobility findings for total score and for single-joints

\begin{tabular}{|c|c|c|c|c|c|c|c|}
\hline \multirow[t]{3}{*}{ Total score/single joint } & \multicolumn{2}{|c|}{ Prevalence of positive findings } & \multirow{3}{*}{$\begin{array}{l}\text { Agreement } \\
\text { Prevalence } \\
\text { of positive } \\
\text { findings (\%) }\end{array}$} & \multirow{2}{*}{\multicolumn{2}{|c|}{ Reliability }} & \multirow{3}{*}{$\begin{array}{l}\text { Prevalence } \\
\text { Index }\end{array}$} & \multirow{3}{*}{$\begin{array}{l}\text { Bias } \\
\text { Index }\end{array}$} \\
\hline & \multirow{2}{*}{$\begin{array}{l}\text { Rater A } \\
n(\%)\end{array}$} & \multirow{2}{*}{$\begin{array}{l}\text { Rater B } \\
n(\%)\end{array}$} & & & & & \\
\hline & & & & Kappa $(95 \%$ Cl) & $\begin{array}{l}\text { Prevalence-adjusted bias-adjusted } \\
\text { kappa-value }(95 \% \mathrm{Cl})\end{array}$ & & \\
\hline$B S \geq 4$ & $3(6)$ & $4(8)$ & 94 & $0.54(0.26-0.82)$ & $0.88(0.66-0.97)$ & 0.86 & 0.02 \\
\hline$B S \geq 5$ & $2(4)$ & $1(2)$ & 98 & $0.66(0.39-0.92)$ & $0.96(0.78-1.00)$ & 0.94 & -0.02 \\
\hline$H d M \geq 4$ & $13(27)$ & $11(22)$ & 92 & $0.78(0.50-1.06)$ & $0.84(0.61-0.95)$ & 0.51 & 0.04 \\
\hline$H d M \geq 5$ & $7(14)$ & $8(16)$ & 94 & $0.76(0.48-1.04)$ & $0.88(0.66-0.97)$ & 0.69 & 0.02 \\
\hline$C S \geq 30$ & $18(37)$ & $14(29)$ & 80 & $0.54(0.26-0.81)$ & $0.59(0.31-0.80)$ & 0.35 & -0.08 \\
\hline 5th Finger, left & $11(22)$ & $7(14)$ & 92 & $0.73(0.46-1.00)$ & $0.84(0.61-0.95)$ & 0.63 & 0.08 \\
\hline 5th Finger, right & $7(14)$ & $4(8)$ & 94 & $0.70(0.43-0.96)$ & $0.88(0.66-0.97)$ & 0.78 & -0.06 \\
\hline Thumb, left & $11(22)$ & $11(22)$ & 100 & $1.00(0.72-1.28)$ & $1.00(0.79-1.00)$ & 0.55 & 0.00 \\
\hline Thumb, right & $7(14)$ & $6(12)$ & 98 & $0.91(0.63-1.19)$ & $0.96(0.78-1.00)$ & 0.73 & -0.02 \\
\hline Elbow, left & $8(16)$ & $5(10)$ & 82 & $0.21(-0.06-0.48)$ & $0.63(0.36-0.82)$ & 0.73 & -0.06 \\
\hline Elbow, right & $7(14)$ & $7(14)$ & 88 & $0.50(0.22-0.78)$ & $0.76(0.50-0.91)$ & 0.71 & 0.00 \\
\hline Shoulder, left & $1(2)$ & $2(4)$ & 98 & $0.66(0.39-0.92)$ & $0.96(0.78-1.00)$ & 0.94 & 0.02 \\
\hline Shoulder, right & $5(10)$ & $4(8)$ & 94 & $0.63(0.36-0.91)$ & $0.88(0.66-0.97)$ & 0.82 & -0.02 \\
\hline Calcaneus, left & $30(61)$ & $22(45)$ & 76 & $0.52(0.26-0.79)$ & $0.51(0.22-0.73)$ & -0.06 & 0.16 \\
\hline Calcaneus, right & $28(57)$ & $19(39)$ & 73 & $0.49(0.22-0.75)$ & $0.47(0.18-0.70)$ & 0.04 & -0.18 \\
\hline Ankle, left & $7(14)$ & $11(22)$ & 80 & $0.33(0.06-0.60)$ & $0.59(0.31-0.80)$ & 0.63 & 0.08 \\
\hline Ankle, right & $6(12)$ & $11(22)$ & 86 & $0.51(0.25-0.77)$ & $0.71(0.46-0.88)$ & 0.65 & 0.10 \\
\hline Big toe, left & $31(63)$ & $35(71)$ & 84 & $0.63(0.36-0.91)$ & $0.67(0.41-0.85)$ & -0.35 & 0.08 \\
\hline Big toe, right & $28(57)$ & $32(65)$ & 84 & $0.66(0.38-0.93)$ & $0.67(0.41-0.85)$ & -0.22 & 0.08 \\
\hline Knee extension, left & $3(6)$ & $6(12)$ & 90 & $0.40(0.13-0.66)$ & $0.80(0.56-0.93)$ & 0.82 & 0.06 \\
\hline Knee extension, right & $1(2)$ & $5(10)$ & 92 & $0.31(0.11-0.51)$ & $0.84(0.61-0.95)$ & 0.88 & 0.08 \\
\hline Knee flexion, left & $39(80)$ & $37(76)$ & 92 & $0.77(0.49-1.04)$ & $0.84(0.61-0.95)$ & -0.55 & -0.04 \\
\hline Knee flexion, right & $38(78)$ & $36(73)$ & 92 & $0.78(0.50-1.06)$ & $0.84(0.61-0.95)$ & -0.51 & -0.04 \\
\hline Trunk flexion & $12(24)$ & $11(22)$ & 98 & $0.94(0.66-1.22)$ & $0.96(0.78-1.00)$ & 0.53 & -0.02 \\
\hline Patella, left & $4(8)$ & $4(8)$ & 100 & $1.00(0.72-1.28)$ & $1.00(0.79-1.00)$ & 0.84 & 0.00 \\
\hline Patella, right & $4(8)$ & $5(10)$ & 98 & $0.88(0.60-1.16)$ & $0.96(0.78-1.00)$ & 0.82 & 0.02 \\
\hline Hip abduction, left & $0(0)$ & $0(0)$ & NA & NA & NA & & \\
\hline Hip abduction, right & $0(0)$ & $0(0)$ & NA & NA & NA & & \\
\hline
\end{tabular}

The hypermobility instruments used in this study were: BS Beighton score, CS Contompasis score, HdM Hospital del Mar, NA Not applicable, none of the participants reached the cut off limit

fine-scale grading of the CS, suggesting that the CS is more sensitive to measurement differences. Another possible explanation could be the small ROM of the calcaneus tilt and the cut-off levels for hypermobility making the judgement less reliable as mentioned above.

The strength of this study is that it was planned and developed in accordance with GRRAS [27] and QAREL [28]. It included a structured protocol with use of size-adjusted goniometers and a comprehensive description of the procedures for performing the assessments illustrated by photographs as recommended [18]. Two experienced physiotherapists, who had trained before the study, performed the measurements. The experience of the rater is important [15] as confirmed in another study showing that inter-rater variability increased as the level of medical education decreased [42]. Furthermore, the stability of joint ROM was taken into account for time intervals of assessments.

The raters stabilized adjacent structures to reduce the risk of false positive hypermobility findings and mainly used passive tests to assure that the end-range position was reached, since passive ROM is greater than active [30].

This study described testing positions since this impact the ROM and an optimal position should facilitate reaching the end-range position. Testing position 
Table 5 Intra-rater reliability for prevalence of positive hypermobility findings for total score and for single-joints

\begin{tabular}{|c|c|c|c|c|c|c|c|}
\hline \multirow[t]{3}{*}{ Total score/single joint } & \multicolumn{2}{|c|}{ Prevalence of positive findings } & \multirow{3}{*}{$\begin{array}{l}\text { Agreement } \\
\text { Prevalence } \\
\text { of positive } \\
\text { findings (\%) }\end{array}$} & \multicolumn{2}{|l|}{ Reliability } & \multirow{3}{*}{$\begin{array}{l}\text { Prevalence } \\
\text { index }\end{array}$} & \multirow{3}{*}{$\begin{array}{l}\text { Bias } \\
\text { index }\end{array}$} \\
\hline & \multirow{2}{*}{$\begin{array}{l}\text { Rater A } \\
n(\%) \\
\end{array}$} & \multirow{2}{*}{$\begin{array}{l}\text { Rater B } \\
n(\%)\end{array}$} & & \multirow[t]{2}{*}{ Kappa (95\% Cl) } & \multirow{2}{*}{$\begin{array}{l}\text { Prevalence-adjusted } \\
\text { bias-adjusted kappa-value } \\
(95 \% \mathrm{Cl})\end{array}$} & & \\
\hline & & & & & & & \\
\hline$B e S \geq 4$ & $3(10)$ & $2(7)$ & 97 & $0.78(0.43-1.14)$ & $0.93(0.64-1.00)$ & 0.83 & -0.03 \\
\hline$B e S \geq 5$ & $3(10)$ & $1(3)$ & 93 & $0.47(0.16-0.78)$ & $0.86(0.54-0.98)$ & 0.86 & -0.07 \\
\hline$H d M \geq 4$ & $7(24)$ & $4(14)$ & 90 & $0.67(0.33-1.01)$ & $0.79(0.45-0.96)$ & 0.62 & -0.10 \\
\hline$H d M \geq 5$ & $2(7)$ & $3(10)$ & 97 & $0.78(0.43-1.14)$ & $0.93(0.64-1.00)$ & 0.83 & 0.03 \\
\hline$C S \geq 30$ & $9(31)$ & $5(17)$ & 72 & $0.27(-0.07-0.60)$ & $0.45(0.06-0.75)$ & 0.52 & -0.14 \\
\hline 5th Finger, left & $3(10)$ & $3(10)$ & 100 & $1.00(0.64-1.36)$ & $1.00(0.66-1.00)$ & 0.79 & 0.00 \\
\hline 5th Finger, right & $3(10)$ & $2(7)$ & 97 & $0.78(0.43-1.14)$ & $0.93(0.64-1.00)$ & 0.83 & -0.03 \\
\hline Thumb, left & $8(28)$ & $5(17)$ & 90 & $0.71(0.36-1.06)$ & $0.79(0.45-0.96)$ & 0.55 & -0.10 \\
\hline Thumb, right & $5(17)$ & $2(7)$ & 90 & $0.52(0.20-0.84)$ & $0.79(0.45-0.96)$ & 0.76 & -0.10 \\
\hline Elbow, left & $5(17)$ & $4(14)$ & 90 & $0.61(0.25-0.97)$ & $0.79(0.45-0.96)$ & 0.69 & -0.03 \\
\hline Elbow, right & $6(21)$ & $4(14)$ & 93 & $0.76(0.41-1.11)$ & $0.86(0.54-0.98)$ & 0.66 & -0.07 \\
\hline Shoulder, left & $1(3)$ & $1(3)$ & 100 & $1.00(0.64-1.36)$ & $1.00(0.66-1.00)$ & 0.93 & 0.00 \\
\hline Shoulder, right & $2(7)$ & $3(10)$ & 90 & $0.35(-0.01-0.70)$ & $0.79(0.45-0.96)$ & 0.83 & 0.03 \\
\hline Calcaneus, left & $14(48)$ & $10(34)$ & 66 & $0.30(-0.05-0.65)$ & $0.31(-0.09-0.64)$ & 0.17 & -0.14 \\
\hline Calcaneus, right & $13(45)$ & $10(34)$ & 76 & $0.50(0.15-0.86)$ & $0.52(0.13-0.79)$ & 0.21 & -0.10 \\
\hline Ankle, left & $5(17)$ & $6(21)$ & 90 & $0.66(0.30-1.03)$ & $0.79(0.45-0.96)$ & 0.62 & 0.03 \\
\hline Ankle, right & $7(24)$ & $6(21)$ & 83 & $0.51(0.14-0.87)$ & $0.66(0.28-0.88)$ & 0.55 & -0.03 \\
\hline Big toe, left & $24(83)$ & $18(62)$ & 79 & $0.51(0.19-0.83)$ & $0.59(0.21-0.84)$ & -0.45 & -0.21 \\
\hline Big toe, right & $15(52)$ & $16(55)$ & 83 & $0.65(0.29-1.02)$ & $0.66(0.28-0.88)$ & -0.07 & 0.03 \\
\hline Knee extension, left & $4(14)$ & $3(10)$ & 97 & $0.84(0.48-1.20)$ & $0.93(0.64-1.00)$ & 0.76 & -0.03 \\
\hline Knee extension, right & $3(10)$ & $4(14)$ & 83 & $0.19(-0.17-0.55)$ & $0.66(0.28-0.88)$ & 0.76 & 0.03 \\
\hline Knee flexion, left & $21(72)$ & $22(76)$ & 90 & $0.73(0.37-1.09)$ & $0.79(0.45-0.96)$ & -0.48 & 0.03 \\
\hline Knee flexion, right & $22(76)$ & $23(79)$ & 97 & $0.90(0.54-1.26)$ & $0.93(0.64-1.00)$ & -0.55 & 0.03 \\
\hline Trunk flexion & $6(21)$ & $6(21)$ & 100 & $1.00(0.64-1.36)$ & $1.00(0.66-1.00)$ & 0.59 & 0.00 \\
\hline Patella, left & $2(7)$ & $3(10)$ & 97 & $0.78(0.43-1.14)$ & $0.93(0.64-1.00)$ & 0.83 & 0.03 \\
\hline Patella, right & $2(7)$ & $5(17)$ & 90 & $0.52(0.20-0.84)$ & $0.79(0.45-0.96)$ & 0.76 & 0.10 \\
\hline Hip abduction, left & $0(0)$ & $0(0)$ & NA & NA & NA & & \\
\hline Hip abduction, right & $0(0)$ & $0(0)$ & NA & NA & NA & & \\
\hline
\end{tabular}

The hypermobility instruments used in this study were: BeS Beighton score, CS Contompasis score, HdM Hospital del Mar, NA Not applicable, none of the participants reached the cut off limit

of adjacent joints is also important. For example, the position of the wrist and the elbow will impact the ROM of the thumb and the fifth finger [13, 38, 39].

A limitation in the present study is that the degree of agreement set at $80 \%$ in the training phase was not specified as recommended by "The International Federation for Manual/Musculoskeletal Medicine" (FIMM) [49]. The rater only measured each subject once to imitate clinical practice. Additionally, another study reported that mobility of joints increased significantly in consecutive measurements [38]. Furthermore, our aim was to measure the participant at the same time point at all testing occasions as it might be important to take this into consideration. However, about half of the participants were not assessed at the same time of the day. This may have influenced the results.

Since both raters were experienced, the use of a third, less experienced rater might have increased the generalizability in a clinical context. However, the generalizability also depends on the raters' ability to follow the testing procedures in a structured protocol. In our study, the raters were experienced. Still, the reliability was not excellent for all measures. For instance, a ROM measurement close to the cut off level for a positive hypermobility finding could be interpreted as positive by one rater and negative by the other. Future implementation of new 
tools to measure ROM will hopefully increase the accuracy.

The choice of using a general population instead of a population diagnosed with GJH might be considered a limitation. However, our main focus was to standardize assessment of joint ROM in degrees, regardless whether the participant was hypermobile or not. The decision to measure joint ROM in a general population with an expected variation in joint mobility aimed to generalize our result to a broader context.

If joint hypermobility is suspected after screening in clinical practice, a standardized joint assessment should be performed for diagnosing GJH. Moreover, to be able to compare GJH studies and to reach international consensus regarding diagnosing GJH-related disorders, a description with standardization of procedures for performing assessments of ROM is needed [18].

\section{Conclusions}

The inter- and intra-rater reliability for total scores was good-to-excellent for the BeS, the CS and the HdM following a structured protocol. However, the inter- and intra-rater reliability was poor-to-moderate in some single joint measurements, indicating difficulties in the performance of these tests. This study includes a structured protocol with a comprehensive description of the performance of joint mobility measurement in several joints. This could be helpful in the first part of the process of standardizing the tests. Standardization for measurement of GJH is needed to provide that the criteria for assessment of GJH is not based on chance and may contribute to minimizing the risk of scoring healthy individuals with GJH. Future studies of reliability and validity should use a standardized protocol to assess persons with GJH. Furthermore, joint measurements other than those included in the BeS are needed, particularly tests assessing ball-and-socket-joints to consider whether these joints are important when diagnosing GJH. In addition, the study indicates that the cut-off value for hypermobility is too high in some joints and needs to be further studied.

\section{Additional files}

Additional file 1: Structured protocol for measurement of range of motion in joints included in the Beighton score, the Contompasis score and the Hospital del Mar Criteria. (DOCX 1226 kb)

Additional file 2: Original description of the hypermobility instruments, the Beighton score, the Contompasis score and the Hospital del Mar Criteria. (DOCX $20 \mathrm{~kb}$ )

\section{Abbreviations}

ANOVA: analysis of variance; BeS: Beighton score; Cl: Confidence interval; FIMM: International Federation for Manual/Musculoskeletal Medicine; GJH: Generalized joint hypermobility; GRRAS: Guidelines for Reporting Reliability and Agreement Studies; HdM: Hospital del Mar criteria; ICC: Intra class correlation; $\mathrm{P}_{\mathrm{a}}$ : Total percentage of agreement; PABAK: Prevalence- adjusted bias-adjusted kappa; QAREL: Quality Appraisal of Reliability Studies; ROM: Range of motion; SD: Standard deviation; SEM: Standard error of measurement; $\mathrm{k}$ : Kappa

\section{Acknowledgements}

The authors would like to thank Aleris Rehab Stockholm which made it possible to conduct this study. A special thanks to Aleris Rehab in

Liljeholmen and Skärholmen who lent the examination rooms.

\section{Funding}

This work was supported by the Aleris Research Fund; Primary Care Research Fund in Region Uppsala and County Council, Uppsala.

\section{Availability of data and materials}

The datasets used and/or analyzed during the current study are available from the corresponding author on reasonable request.

\section{Authors' contributions}

AS and KA equally contributed to the study as first authors and wrote the manuscript. They made substantial contributions to conception and design, acquisition, analysis and interpretation of data. ERB, EKB, RP, CO, LNW, PK contributed in designing the study. All authors contributed with interpretation of the results and writing the manuscript. RP contributed to the data analysis. All authors critically revised and approved the final version of the manuscript.

\section{Competing interest}

The authors declare that they have no competing interests.

Ethics approval and consent to participate

Informed written consent was obtained from all participants upon their inclusion in the study. The study was conducted between October 2014 and March 2015 and was approved by the Regional Ethical Review Board in Stockholm: Dnr, 2014/655-31/4.

Consent for publication

Not applicable.

\section{Publisher's Note}

Springer Nature remains neutral with regard to jurisdictional claims in published maps and institutional affiliations.

\section{Author details}

${ }_{1}^{1}$ Department of Public Health and Caring Sciences, Uppsala University, Husargatan 3, Box 564, 75237 Uppsala, Sweden. Karolinska Institutet, Department of Neurobiology, Care Sciences and Society, Division of Physiotherapy, Huddinge, Sweden. ${ }^{3}$ Department of Obstetrics and Gynecology, Akershus University Hospital, Lørenskog, Norway. ${ }^{4}$ Academic Primary Healthcare Centre, Stockholm County Council, Huddinge, Sweden.

Received: 8 February 2018 Accepted: 2 October 2018

Published online: 17 October 2018

References

1. Ross J, Grahame R. Joint hypermobility syndrome. BMJ. 2011;342:C7167.

2. Engelbert $\mathrm{RH}$, Juul-Kristensen $B$, Pacey $\mathrm{V}$, de Wandele I, Smeenk $\mathrm{S}$, Woinarosky $\mathrm{N}$, et al. The evidence-based rationale for physical therapy treatment of children, adolescents, and adults diagnosed with joint hypermobility syndrome/hypermobile Ehlers Danlos syndrome. Am J Med Genet C Semin Med Genet. 2017:175:158-67.

3. Grahame R, Bird HA, Child A. The revised (Brighton 1998) criteria for the diagnosis of benign joint hypermobility syndrome (BJHS). J Rheumatol. 2000;27:1777-9.

4. Rombaut L, Malfait F, De Wandele I, Thijs Y, Palmans T, De Paepe A, et al. Balance, gait, falls, and fear of falling in women with the hypermobility type of Ehlers-Danlos syndrome. Arthritis Care Res. 2011;63:1432-9.

5. Grahame R. The hypermobility syndrome. Ann Rheum Dis. 1990;49:199-200.

6. Silman AJ, Haskard D, Day S. Distribution of joint mobility in a normal population: results of the use of fixed torque measuring devices. Ann Rheum Dis. 1986;45:27-30.

7. Remvig $L$, Jensen DV, Ward RC. Are diagnostic criteria for general joint hypermobility and benign joint hypermobility syndrome based on 
reproducible and valid tests? A review of the literature. J Rheumatol. 2007; 34:798-803.

8. Hakim A, Grahame R. Joint hypermobility. Best Pract Res Clin Rheumatol. 2003;17:989-1004.

9. Larsson LG, Baum J, Mudholkar GS, Srivastava DK. Hypermobility: prevalence and features in a Swedish population. Br J Rheumatol. 1993;32:116-9.

10. Remvig L, Engelbert RH, Berglund B, Bulbena A, Byers PH, Grahame R, et al. Need for a consensus on the methods by which to measure joint mobility and the definition of norms for hypermobility that reflect age, gender and ethnic-dependent variation: is revision of criteria for joint hypermobility syndrome and Ehlers-Danlos syndrome hypermobility type indicated? Rheumatology (Oxford). 2011;50:1169-71.

11. Remvig L, Flycht L, Christensen KB, Juul-Kristensen B. Lack of consensus on tests and criteria for generalized joint hypermobility, Ehlers-Danlos syndrome: hypermobile type and joint hypermobility syndrome. Am J Med Genet A. 2014;164a:591-6.

12. Bulbena A, Duro JC, Porta M, Faus S, Vallescar R, Martin-Santos R. Clinical assessment of hypermobility of joints: assembling criteria. J Rheumatol. 1992;19:115-22.

13. Beighton P, Solomon L, Soskolne CL. Articular mobility in an African population. Ann Rheum Dis. 1973;32:413-8.

14. Carter C, Wilkinson J. Persistent joint laxity and congenital dislocation of the hip. J Bone Joint Surg Br. 1964:46:40-5.

15. Juul-Kristensen B, Rogind H, Jensen DV, Remvig L. Inter-examiner reproducibility of tests and criteria for generalized joint hypermobility and benign joint hypermobility syndrome. Rheumatology (Oxford). 2007;46: 1835-41.

16. Boyle KL, Witt P, Riegger-Krugh C. Intrarater and interrater reliability of the Beighton and Horan joint mobility index. J Athl Train. 2003;38:281-5.

17. Junge $T$, Jespersen $E$, Wedderkopp N, Juul-Kristensen B. Inter-tester reproducibility and inter-method agreement of two variations of the Beighton test for determining generalised joint hypermobility in primary school children. BMC Pediatr. 2013;13:214

18. Juul-Kristensen B, Schmedling K, Rombaut L, Lund H, Engelbert RH. Measurement properties of clinical assessment methods for classifying generalized joint hypermobility-a systematic review. Am J Med Genet C Semin Med Genet. 2017;175:116-47.

19. McNerney JE, Johnston WB. Generalized ligamentous laxity, hallux abducto valgus and the first metatarsocuneiform joint. J Am Podiatr Assoc. 1979;69: 69-82.

20. Mikkelsson M, Salminen JJ, Kautiainen H. Joint hypermobility is not a contributing factor to musculoskeletal pain in pre-adolescents. J Rheumatol. 1996:23:1963-7.

21. Hicks GE, Fritz JM, Delitto A, Mishock J. Interrater reliability of clinical examination measures for identification of lumbar segmental instability. Arch Phys Med Rehabil. 2003;84:1858-64.

22. Evans $\mathrm{AM}$, Rome $\mathrm{K}$, Peet $\mathrm{L}$. The foot posture index, ankle lunge test, Beighton scale and the lower limb assessment score in healthy children: a reliability study. J Foot Ankle Res. 2012;5:1.

23. Ohman A, Westblom C, Henriksson M. Hypermobility among school children aged five to eight years: the hospital del mar criteria gives higher prevalence for hypermobility than the Beighton score. Clin Exp Rheumatol. 2014:32:285-90.

24. Beighton P, De Paepe A, Steinmann B, Tsipouras P, Wenstrup RJ. EhlersDanlos syndromes: revised nosology, Villefranche, 1997. Ehlers-Danlos National Foundation (USA) and Ehlers-Danlos support group (UK). Am J Med Genet. 1998:77:31-7.

25. Aartun E, Degerfalk A, Kentsdotter L, Hestbaek L. Screening of the spine in adolescents: inter- and intra-rater reliability and measurement error of commonly used clinical tests. BMC Musculoskelet Disord. 2014;15:37.

26. van de Pol RJ, van Trijffel E, Lucas C. Inter-rater reliability for measurement of passive physiological range of motion of upper extremity joints is better if instruments are used: a systematic review. J Physiother. 2010;56:7-17.

27. Kottner J, Audige L, Brorson S, Donner A, Gajewski BJ, Hrobjartsson A, et al. Guidelines for reporting reliability and agreement studies (GRRAS) were proposed. Int J Nurs Stud. 2011;48:661-71.

28. Lucas NP, Macaskill P, Irwig L, Bogduk N. The development of a quality appraisal tool for studies of diagnostic reliability (QAREL). J Clin Epidemiol. 2010;63:854-61.

29. Wahlstedt C, Rasmussen-Barr E. Anterior cruciate ligament injury and ankle dorsiflexion. Knee Surg Sports Traumatol Arthrosc. 2015;23:3202-7.
30. Clarkson H M, editior. Musculoskeletal assessment: joint motion and muscle testing. 3rd ed. Philadelphia, USA: Lippincott Williams \& Wilkins; 2013.

31. Shrout PE, Fleiss JL. Intraclass correlations: uses in assessing rater reliability. Psychol Bull. 1979:86:420-8.

32. Portney L, Watkins $M$, editors. Foundations of clinical research: applications to practice. 3rd ed. upper Saddle River. USA: Pearson Prentice Hall; 2009. p. 892.

33. Weir JP. Quantifying test-retest reliability using the intraclass correlation coefficient and the SEM. J Strength Cond Res. 2005;19:231-40.

34. Hopkins WG. Measures of reliability in sports medicine and science. Sports Med. 2000;30:1-15.

35. Sim J, Wright CC. The kappa statistic in reliability studies: use, interpretation, and sample size requirements. Phys Ther. 2005;85:257-68.

36. Landis JR, Koch GG. The measurement of observer agreement for categorical data. Biometrics. 1977;33:159-74.

37. Walter SD, Eliasziw M, Donner A. Sample size and optimal designs for reliability studies. Stat Med. 1998;17:101-10.

38. Dijkstra PU, de Bont $L G$, van der Weele $L T$, Boering G. Joint mobility measurements: reliability of a standardized method. Cranio. 1994;12:52-7.

39. Hirsch C, Hirsch M, John MT, Bock JJ. Reliability of the Beighton hypermobility index to determinate the general joint laxity performed by dentists. J Orofac Orthop. 2007;68:342-52.

40. Prushansky T, Dvir Z. Cervical motion testing: methodology and clinical implications. J Manip Physiol Ther. 2008;31:503-8.

41. Karim A, Millet V, Massie K, Olson S, Morganthaler A. Inter-rater reliability of a musculoskeletal screen as administered to female professional contemporary dancers. Work. 2011:40:281-8.

42. Hansen ADR, Kristensen JH, Baggerss J, Remvig L. Interexaminer reliability of selected tests for hypermobility. J Orth Med. 2002;25:48-51.

43. Smits-Engelsman B, Klerks M, Kirby A. Beighton score: a valid measure for generalized hypermobility in children. J Pediatr. 2011;158:119-23 23.e1-4.

44. Boone DC, Azen SP, Lin CM, Spence C, Baron C, Lee L. Reliability of goniometric measurements. Phys Ther. 1978;58:1355-60.

45. Smith DS. Measurement of joint range--an overview. Clin Rheum Dis. 1982; 8(3):523-31

46. Greene W, Heckman J, editors. American Academy of Orthopaedic surgeons. The clinical measurement of joint motion. First ed. Illinois: Rosemont; 1994

47. Nilsson C, Wykman A, Leanderson J. Spinal sagittal mobility and joint laxity in young ballet dancers. A comparative study between first-year students at the Swedish ballet school and a control group. Knee Surg Sports Traumatol Arthrosc. 1993;1:206-8.

48. McCormack M, Briggs J, Hakim A, Grahame R. Joint laxity and the benign joint hypermobility syndrome in student and professional ballet dancers. $J$ Rheumatol. 2004:31:173-8.

49. Patijn J, editor. FIMM Scientific Committee. Reproducibility and validity studies of Diagnostic Procedures in Manual/Musculoskeletal Medicine. Protocol formats. 3rd ed. Avaliable from: http://www.fimm-online.com/pub/ en/data/objects/reproduciblity_validity.pdf.

Ready to submit your research? Choose BMC and benefit from:

- fast, convenient online submission

- thorough peer review by experienced researchers in your field

- rapid publication on acceptance

- support for research data, including large and complex data types

- gold Open Access which fosters wider collaboration and increased citations

- maximum visibility for your research: over $100 \mathrm{M}$ website views per year

At $\mathrm{BMC}$, research is always in progress.

Learn more biomedcentral.com/submissions 